\title{
Expression of miR-124 in gastric adenocarcinoma and the effect on proliferation and invasion of gastric adenocarcinoma SCG-7901 cells
}

\author{
JIANFENG MU $^{1 *}$, HELEI WANG ${ }^{1 *}$, XIAODONG WANG ${ }^{2}$ and PENGDA SUN ${ }^{3}$ \\ ${ }^{1}$ Department of Gastric Colorectal Surgery, The First Hospital of Jilin University, Changchun, \\ Jilin 130021; Departments of ${ }^{2}$ Endoscopy and ${ }^{3}$ Gastrointestinal Nutrition and Hernia Surgery, \\ The Second Hospital of Jilin University, Changchun, Jilin 130041, P.R. China
}

Received June 11, 2018; Accepted January 7, 2019

DOI: $10.3892 / 01.2019 .9981$

\begin{abstract}
Expression of miR-124 in gastric adenocarcinoma cell line SGC-7901 and its effect on biological functions was investigated. Expression of miR-124 in cancer tissues and paracancerous tissues of gastric adenocarcinoma patients was detected by reverse transcription-quantitative polymerase chain reaction (RT-qPCR). RT-qPCR was used to detect the expression of miR-124 in human normal gastric epithelial cells GES-1 and gastric adenocarcinoma SGC-7901 cells. Cells in miR-124 group were transfected with miR-124 agomir, cells in $\mathrm{NC}$ group were transfected with agomir-negative control sequence and cells in the control group were not transfected. MTT assay was used to detect cell proliferation, and Transwell invasion assay to detect cell invasion ability, and the effect of transfected miR-124 agonist on the proliferation and invasive ability of gastric adenocarcinoma cells was evaluated. RT-qPCR results showed that miR-124 expression was significantly downregulated in gastric adenocarcinoma tumor tissues compared with paracancerous tissues. Compared with cells of normal human gastric epithelial cell line GES-1, the expression of miR-124 human gastric adenocarcinoma SGC-7901 cells was significantly downregulated. At $12 \mathrm{~h}$, there was no significant difference in OD at $490 \mathrm{~nm}$ in the three groups ( $\mathrm{P}>0.05)$. OD (490) in the three groups showed a gradual upward trend. After transfection, proliferation curves of the three groups showed an upward trend, proliferation rate of miR-124 group was significantly lower than that of NC and control groups $(\mathrm{P}<0.05)$. The number of invading cells in
\end{abstract}

Correspondence to: Dr Pengda Sun, Department of Gastrointestinal Nutrition and Hernia Surgery, The Second Hospital of Jilin University, 218 Ziqiang Street, Nanguan, Changchun, Jilin 130041, P.R. China

E-mail:sqb77q@163.com; spd52291@163.com

${ }^{*}$ Contributed equally

Key words: miR-124, gastric adenocarcinoma, SGC-7901, proliferation, invasion
miR-124 group was significantly lower than that in NC group and control group, but there was no significant difference in the number of cell invasion between the NC and control groups. miR-124 can inhibit the proliferation and invasion of gastric adenocarcinoma cells. Downregulation of miR-124 expression in gastric adenocarcinoma may be closely related to the development of gastric adenocarcinoma.

\section{Introduction}

Gastric cancer is one of the most common malignant tumors in the digestive system. In 2015, the American Cancer Society reported 24,590 new cases of gastric cancer in the United States, of which $63.20 \%$ were male (1). Of the 1 million new cases of gastric cancer in the world each year, Asians account for $74 \%$ (2). Incidence of gastric cancer has racial and regional characteristics (3). Gastric adenocarcinoma as the most common type of gastric cancer originates from the gastric glandular epithelial cells accounting for $\sim 95 \%$ of gastric cancer (4). Pathogenesis of gastric cancer is not yet clear, and may be closely related to dietary habits and Helicobacter pylori (5). Oncogenes and suppressor genes, changes in epigenetics and changes in chromosome stability, are likely to alter cell proliferation, apoptosis, and invasion, and thus participate in the development of gastric cancer (6).

Numerous findings have shown that a variety of lncRNAs and miRNAs are involved in the occurrence of gastric cancer (7). miRNAs ( $22 \mathrm{bp})$ are endogenous RNAs that do not encode protein, but play a regulatory role at the level of transcription and translation (8). miRNAs can bind to the 3'-untranslated region sequence of the target mRNA through base pairing, thereby degrading target mRNA or preventing translation of target mRNA, and play an important role in tumor cell proliferation, differentiation, and malignant transformation (9).It has been shown that miR-124 is downregulated in many cancer tissues such as liver cancer and can inhibit tumor growth $(5,10)$. Liu et al $(11)$ found that miR-124 may be a predictor of LNM and tumor stage in gastric cancer. In order to understand the role of miR-124 in gastric cancer, the present study investigated the expression of miR-124 in gastric cancer SGC-7901 cells and its effect on biological 
function. Our study provides a new potential molecular target for the treatment of gastric cancer.

\section{Materials and methods}

Cells and reagents. Gastric adenocarcinoma SGC-7901 cell line, human normal gastric mucosal epithelial GES-1 cells (Shanghai Guandao Bio-engineering Co., Ltd., Shanghai, China); miR-124 agomir and negative control sequence (Shanghai GenePharma Co., Ltd., Shanghai, China); fetal bovine serum and RPMI-1640 medium (Shanghai Hengyuan Biotechnology Co., Ltd., Shanghai, China); EasyPure miRNA kit, TransScript Green miRNA Two-Step qRT-PCR SuperMix kit (Beijing TransGen Biotech Co., Ltd., Beijing, China); Lipofectamine ${ }^{\circledR} 3000$ transfection reagent and TRIzol reagent (Thermo Fisher Scientific, Inc., Waltham, MA, USA); qPCR primers (Sangon Biotech Co., Ltd., Shanghai, China); MTT (Yeasen Biotechnology, Co., Ltd., Shanghai, China); Transwell cell (Beijing Yiming Fuxing Biotechnology, Beijing, China).

The study was approved by the Ethics Committee of The First Hospital of Jilin University (Changchun, China). Signed informed consents were obtained from the patients or the guardians.

$R T-q P C R$ detection of miR-124 expression in cancer and adjacent tissues. Fifty cases of identified gastric adenocarcinoma and paracancerous tissues were obtained in The First Hospital of Jilin University. RT-qPCR was used to detect the expression of miR-124 in cancer and adjacent tissues. TRIzol reagent was used to extract total RNA from cancer and paracancerous tissues. After purification using an EasyPure miRNA kit, the concentration and purity of RNA were detected by UV spectrophotometer. RNA samples with a A260/A280 ratio of 1.8-2.0 were subjected to reverse transcription in accordance with the reverse transcription kit instructions: $37^{\circ} \mathrm{C}$ for $1 \mathrm{~h}$ and $85^{\circ} \mathrm{C}$ 5 sec. qPCR reaction system was prepared strictly in accordance with the qPCR kit instructions. Reaction conditions of PCR reaction: $94^{\circ} \mathrm{C}$ for $30 \mathrm{sec}$, followed by 40 cycles of $94^{\circ} \mathrm{C}$ for $5 \mathrm{sec}$ and $60^{\circ} \mathrm{C}$ for $30 \mathrm{sec}$. GAPDH was used as the endogenous control and the primer sequences are listed in Table I. The $2^{-\Delta \mathrm{Cq}}$ method was used to process qRT-PCR results (12).

Gastric adenocarcinoma tissue inclusion criteria (13): i) pathological examination confirmed gastric adenocarcinoma; ii) intended for surgical treatment; iii) patients with normal functions of important organs such as heart and lung and patients were able to withstand surgical resections; iv) signed informed consent. Exclusion criteria were: i) patients with postoperative recurrence of gastric cancer and recurrent gastric cancer; ii) history of abdominal surgery, abdominal abscess, and peritoneal inflammation; iii) patients with important organ dysfunction; iv) recent use of hormone drugs, blood products and immunosuppressive agents; v) received preoperative radiation therapy, chemotherapy and other antitumor therapy.

Cell transfection. Cells were divided into miR-124 agomir group, NC group and blank group. Cells were incubated with RPMI-1640 medium containing $10 \% \mathrm{FBS}$ at $37^{\circ} \mathrm{C}$ in a $5 \% \mathrm{CO}_{2}$ incubator. Transfection was performed when the cell confluence reached $80 \%$ and transfection was performed strictly in accordance with the instructions of Lipofectamine ${ }^{\circledR} 3000$. Cells in miR-124 group were transfected with miR-124 agomir, cells in NC group were transfected with agomir negative control sequence and cells in control group were not transfected. Cells were incubated for $5 \mathrm{~min}$ at room temperature and plasmid DNA and liposome complexes were mixed with the cells. Cultured cells were incubated at $37^{\circ} \mathrm{C}$ with $5 \% \mathrm{CO}_{2}$ for 2 days and transfection was checked. Then, the cell was collected for subsequent experimentation.

$R T$-qPCR detection of miR-124 expression in different groups of cells. RT-qPCR was used to detect the expression of miR-124 in each group. Specific methods used were the same as in 'Cells and reagents'.

MTT assay to detect cell proliferation. When the cell confluency reached $80 \%$, cell suspensions were prepared with a cell density of $2 \times 10^{4}$ cells $/ \mathrm{ml}$. Then, $200 \mu \mathrm{l}$ cell suspension was added into each well of a 96 -well plate. Cell viability was measured by MTT assay. A total of $20 \mu \mathrm{l}$ of $5 \mathrm{mg} / \mathrm{ml} \mathrm{MTT}$ solution was added into each well at 12, 24, 48, 72, and $96 \mathrm{~h}$ after the initiation of cell culture for color development. After incubation for another $4 \mathrm{~h}, 150 \mu \mathrm{l}$ Formanzan Lysing Solution was added into each well, followed by shaking at room temperature for $10 \mathrm{~min}$. When crystals were completely dissolved, absorbance (OD) at the wavelength of $490 \mathrm{~nm}$ was measured using a microplate reader. The measurement was repeated 3 times.

Transwell invasion assay to detect cell invasion ability. Serum-free DMEM medium was used to starve cultured cells for $12 \mathrm{~h}$ to remove the effects from serum. When cell confluence reached $80 \%$, cells were resuspended with the invasion buffer. Cells were counted and cell density was adjusted to $5 \times 10^{4} / \mathrm{ml}$. A total of $200 \mu \mathrm{l}$ of cell suspension was evenly spread over 6-well Transwell upper chamber (cat. no. 354480; BD Biosciences, Franklin Lakes, NJ, USA) polycarbonate membrane and $600 \mu \mathrm{l}$ of DMEM medium containing $20 \%$ fetal bovine serum was added into the lower chamber. The cells were cultured at $37^{\circ} \mathrm{C}$ with $5 \% \mathrm{CO}_{2}$ for $24 \mathrm{~h}$. A cotton swab was used to gently wipe off the uninvaded cells on polycarbonate membrane. After washing with PBS 3 times, the membrane was fixed with $4 \%$ paraformaldehyde for $10 \mathrm{~min}$, followed by crystal violet staining for $10 \mathrm{~min}$. After washing with PBS 3 times, 5 visual fields (x400) were selected under a microscope (Olympus Corporation, Tokyo, Japan) to count cells and calculate the average value.

Statistical analysis. SPSS20.0 [AsiaAnalytics (formerly SPSS China), Shanghai, China] statistical software package was used to test and analyze the data. Measured data were expressed as mean \pm standard deviation. ANOVA followed by LSD test was used for comparisons among three groups. Comparisons of data at different time-points in the same group of MTT assay were performed by repeated measures analysis of variance. Significance level was $\alpha=0.05$.

\section{Results}

Expression of miR-124 in gastric adenocarcinoma tissues and adjacent tissues. Expression level of miR-124 in gastric 
Table I. qPCR primer sequences.

\begin{tabular}{lcc} 
Gene & Forward & Reverse \\
\hline GAPDH & 5'-GGTGGTGCTAAGCGTGTTA-3' & 5'-CCCTCCACAATGCCAA-3' \\
$m i R-124$ & 5'-TAAGGCACGCGGTGAATG-3' & 5'-TGGTGTCGTGGAGTCG-3'
\end{tabular}

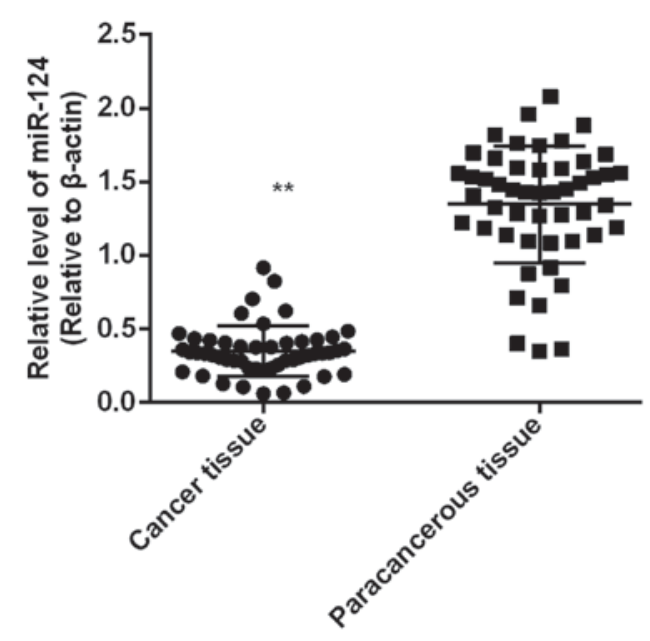

Figure 1. Expression of miR-124 in gastric adenocarcinoma tissues and adjacent tissues. Expression level of miR-124 in gastric adenocarcinoma tissues was significantly lower than that in paracancerous tissues $(\mathrm{P}<0.01) .{ }^{* *} \mathrm{P}<0.01$.

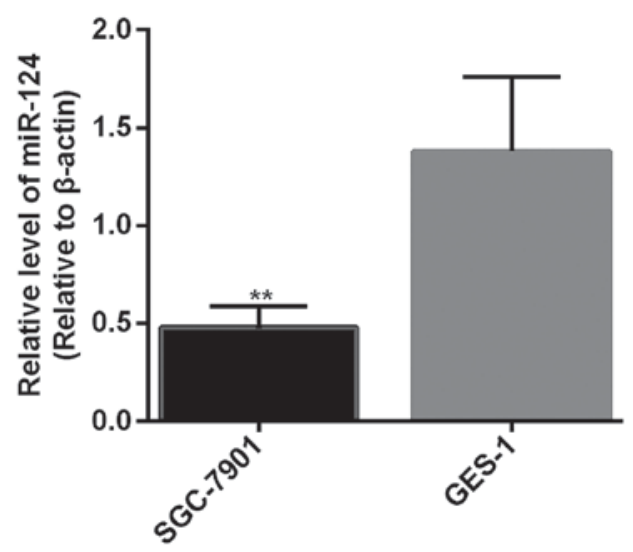

Figure 2. Expression of miR-124 in GES-1 and SGC-7901 before transfection. Expression level of miR-124 in cells of SGC-7901 cell line was significantly lower than that in GES-1 cell line $(\mathrm{P}<0.01) .{ }^{* *} \mathrm{P}<0.01$.

adenocarcinoma tissue $(0.35 \pm 0.02)$ was significantly lower than that in paracancerous tissue $(1.34 \pm 0.06)(\mathrm{P}<0.01)$. Expression level of miR-124 in cancer tissue was lower than that in corresponding paracarcinoma tissues in 45 cases, and the downregulation rate was $90 \%$ (Fig. 1).

Expression of miR-124 in GES-1 and SGC-7901 before transfection. Expression level of miR-124 in cells of the SGC-7901 cell line $(0.48 \pm 0.11)$ was significantly lower than that in cells of the GES-1 cell line $(1.38 \pm 0.38)(\mathrm{P}<0.01)$ (Fig. 2).

Expression of miR-124 in cells of miR-124, NC and control groups after transfection. Relative expression levels of miR-124

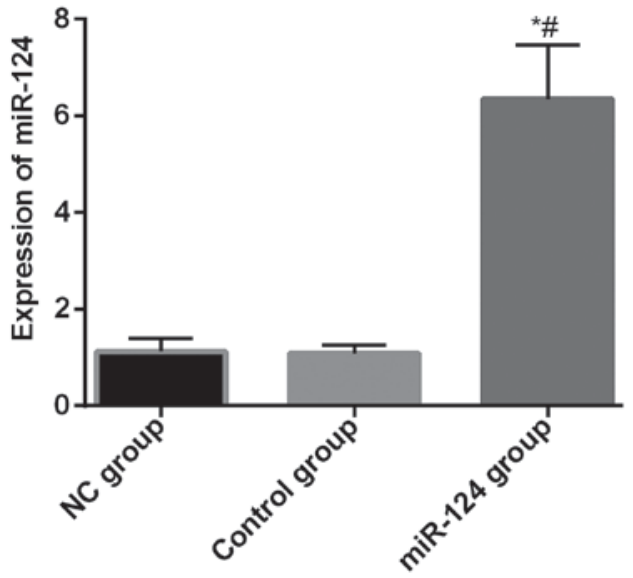

Figure 3. Expression of miR-124 in miR-124 and NC and control groups after transfection. Relative expression level of miR-124 in NC group, control group and miR-12 group was $1.12 \pm 0.28,1.09 \pm 0.17,6.35 \pm 1.11$, respectively. Relative expression level of miR-124 in miR-12 group was significantly higher than that in the NC group and control group $(\mathrm{P}<0.05)$. There was no difference between the $\mathrm{NC}$ and control groups $(\mathrm{P}>0.05)$. ${ }^{*} \mathrm{P}<0.05$, compared with $\mathrm{NC}$ group. ${ }^{\#} \mathrm{P}<0.05$, compared with control group.

Table II. OD values of each group.

\begin{tabular}{lcccrc}
\hline Time-points (h) & $\begin{array}{c}\text { NC } \\
\text { group }\end{array}$ & $\begin{array}{c}\text { miR-124 } \\
\text { group }\end{array}$ & $\begin{array}{c}\text { Control } \\
\text { group }\end{array}$ & F-value & P-value \\
\hline 12 & $0.14 \pm 0.03$ & $0.11 \pm 0.02$ & $0.13 \pm 0.04$ & 2.17 & 0.14 \\
24 & $0.32 \pm 0.06$ & $0.22 \pm 0.04^{\mathrm{a}, \mathrm{b}}$ & $0.35 \pm 0.05$ & 16.25 & $<0.001$ \\
48 & $0.47 \pm 0.09$ & $0.31 \pm 0.06^{\mathrm{a}, \mathrm{b}}$ & $0.49 \pm 0.08$ & 14.52 & $<0.001$ \\
72 & $0.58 \pm 0.10$ & $0.39 \pm 0.08^{\mathrm{a}, \mathrm{b}}$ & $0.61 \pm 0.09$ & 15.69 & $<0.001$ \\
96 & $0.61 \pm 0.11$ & $0.44 \pm 0.09^{\mathrm{a}}$ & $0.65 \pm 0.12$ & 9.70 & $<0.001$ \\
F-value & 49.45 & 39.25 & 61.20 & & \\
P-value & $<0.001$ & $<0.001$ & $<0.001$ & & \\
\hline
\end{tabular}

${ }^{a} \mathrm{P}<0.05$, compared with $\mathrm{NC}$ group at the same time-point. ${ }^{\mathrm{b}} \mathrm{P}<0.05$, compared with the previous time-point in the same group.

in NC group, control group and miR-12 group were $1.12 \pm 0.28$, $1.09 \pm 0.17,6.35 \pm 1.11$, respectively. Relative expression level of miR-124 in miR-12 group was significantly higher than that in the $\mathrm{NC}$ and control groups $(\mathrm{P}<0.05)$, and there was no difference between the NC and control groups ( $\mathrm{P}>0.05)$ (Fig. 3).

Cell proliferation after miR-124 transfection. At $12 \mathrm{~h}$ after transfection, there was no significant difference in OD at $490 \mathrm{~nm}$ among the 3 groups ( $>0.05$ ). OD (490) of miR-124 group, $\mathrm{NC}$ group and control group at $24 \mathrm{~h}$ were $0.22 \pm 0.04$, $0.32 \pm 0.06$ and $0.35 \pm 0.05$, respectively, OD (490) and miR-124 group was significantly lower than that in $\mathrm{NC}$ group and control 


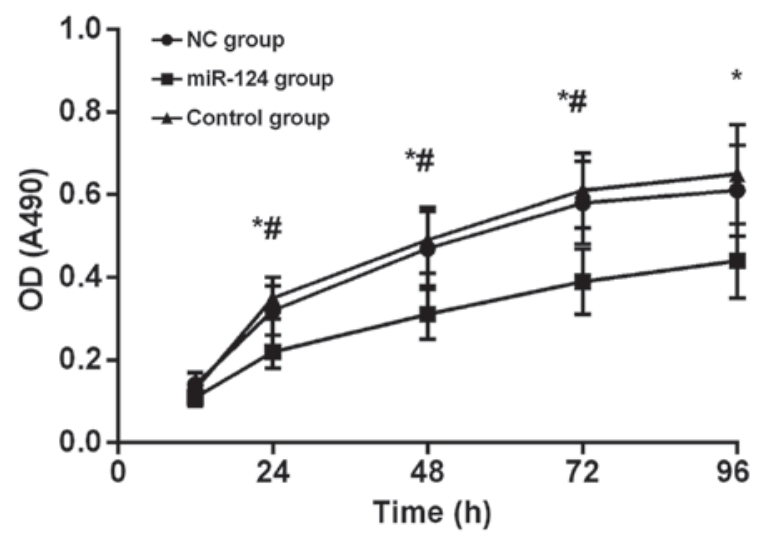

Figure 4. MTT detection of cell proliferation. At $12 \mathrm{~h}$, there was no significant difference in OD at $490 \mathrm{~nm}$ among 3 groups ( $P>0.05)$. OD (490) in 3 groups showed a gradual upward trend. However, at $24 \mathrm{~h}$, OD values in miR-124 group were always significantly lower than those in NC group and the contro group $(\mathrm{P}<0.01)$, and there was no difference between NC group and control group $(\mathrm{P}>0.05)$. OD values of the three groups at 24,48 , and $72 \mathrm{~h}$ were all higher than those at the previous time-point $(\mathrm{P}<0.01)$, and there was no significant difference between $96 \mathrm{~h}$ and $72 \mathrm{~h}(\mathrm{P}>0.05)$. ${ }^{*} \mathrm{P}<0.05$, compared with $\mathrm{NC}$ group at the same time-point. ${ }^{\#} \mathrm{P}<0.05$, compared with the previous time-point in the same group.

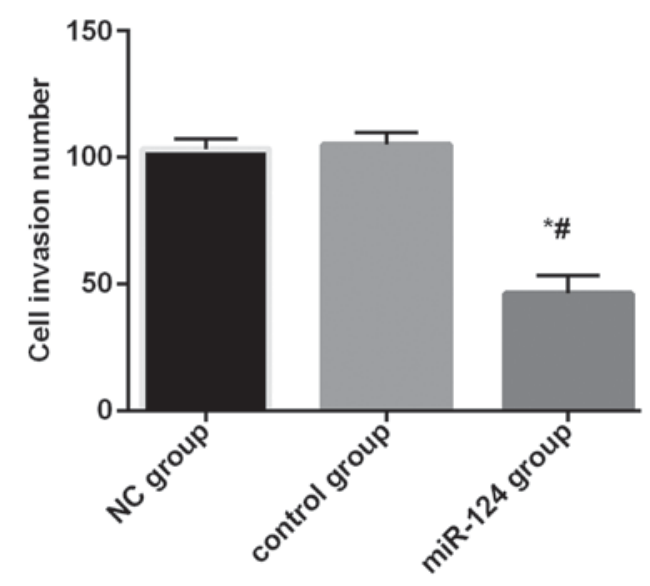

Figure 5. Cell invasion ability. The number of invading cells in miR-124 group was significantly lower than that of the $\mathrm{NC}$ and control groups $(\mathrm{P}<0.01)$. There was no significant difference in the number of invading cells between the $\mathrm{NC}$ and control groups. ${ }^{*} \mathrm{P}<0.05$, compared with $\mathrm{NC}$ group. ${ }^{*} \mathrm{P}<0.05$, compared with control group.

group $(\mathrm{P}<0.01)$. The difference between $\mathrm{NC}$ group and control group was not statistically significant $(\mathrm{P}>0.05)$. OD (490) in all three groups showed a gradual upward trend, but at $24 \mathrm{~h}, \mathrm{OD}$ (490) in miR-124 group was significantly lower than that in NC group and control group $(\mathrm{P}<0.01)$, but there was no difference between NC group and control group ( $\mathrm{P}>0.05)$. OD values of all 3 groups at 24, 48 , and $72 \mathrm{~h}$ were all higher than those at the previous time-point $(\mathrm{P}<0.01)$, and there was no significant difference between $96 \mathrm{~h}$ and $72 \mathrm{~h}(\mathrm{P}>0.05)$. OD values at different time-points in each group are listed in Table II, and the MTT proliferation curve is shown in Fig. 4.

Invasion ability of cells after miR-124 transfection. The number of invading cells in miR-124 group, $\mathrm{NC}$ group, and control group was $46.17 \pm 7.13,103.13 \pm 4.14$, and $105.11 \pm 4.62$, respectively. The number of invading cells in miR-124 group was significantly lower than that of the $\mathrm{NC}$ group and control group $(\mathrm{P}<0.01)$. There was no significant difference in the number of invading cells between NC group and control group (Fig. 5).

\section{Discussion}

In China, with the gradual increase of economic level, incidence and mortality of gastric cancer have also increased year by year (14), and the onset age of disease is becoming younger and younger (15). Symptoms of early gastric cancer are not obvious. Most patients were in advanced or late metastasis stage at the time of diagnosis. More than half of the patients have recurrence after surgery. Chemotherapy is also ineffective in some cases due to multiple drug resistance (16). miRNAs play an important role in the development of tumors and have been the focus of research in recent years (17). Studies have shown that miR-124 can inhibit the progression of cancer such as liver cancer and cervical cancer, promote the differentiation of CD133 tumors, and induce tumor cell apoptosis (18). Studies have shown that miR-124 is downregulated in gastric cancer, but the mechanism of action of miR-124 in gastric cancer remains unclear. Therefore, the expression of miR-124 in gastric cancer SGC-7901 cells and its effect on biological function were explored in this study and the role of miR-124 in gastric cancer was evaluated.

Expression level of miR-124 in gastric adenocarcinoma tissues was significantly lower than that in paracancerous tissues and expression level of miR-124 in SGC-7901 cells was significantly lower than that in GES-1 cells, indicating that miR-124 was downregulated in gastric cancer tissues. Hu et al (19) also found that miR-124 expression level was significantly reduced in gastric adenocarcinoma tissue samples and cell lines. After transfection, although proliferation curves of all three groups showed an upward trend, cell proliferation rate in miR-124 group was significantly lower than that in NC group and control group, indicating inhibited cell proliferation after miR-124 transfection. Pan et al (20) found that lentiviral vectors that stably express miR124 can inhibit the growth, migration, and invasion of gastric cancer cells. Li et al (21) found that miR-124 can inhibit cell invasion and epithelial mesenchymal transformation by inhibiting Snail2 expression.

In this study, the downregulated expression of miR-124 in gastric adenocarcinoma was verified at both tissue and cell levels. We conclude that miR-124 is downregulated in gastric adenocarcinoma tissue and miR-124 can inhibit the proliferation and invasion of gastric adenocarcinoma cells and inhibit the development of gastric adenocarcinoma. However, only one cell line was used and conclusions may be biased. We will include more cell lines in our future studies. Although MTT and Transwell invasion experiments have shown that miR-124 can inhibit the proliferation and invasion of gastric adenocarcinoma cells, the downstream target genes and specific signaling pathways remain to be further studied.

Through literature investigations, we found that downstream target genes of miR-124 are SPHK1 and ROCK. These target genes will be verified in our subsequent studies and relevant pathways will also be identified. Xia et al (22) found that miR-124 can downregulate SPHK1. The expression of miR-124 in gastric cancer tissues is reduced and the silencing effect on SPHK1 is relieved. SPHK1 expression is increased in 
gastric cancer and closely related to the shortened survival time of patients. Hu et al (19) found that miR-124 overexpression inhibits ROCK1 and miR-124 functions as a tumor suppressor by targeting ROCK1. Jiang et al (23) found that miR-124 negatively regulates Notch1 signaling by targeting JAG1 to inhibit GC cell growth, migration, invasion and induce cell cycle arrest. In conclusion, miR-124 can inhibit the proliferation and invasion of gastric adenocarcinoma cells. Downregulation of miR-124 expression in gastric adenocarcinoma may be closely related to the development of gastric adenocarcinoma.

\section{Acknowledgements}

Not applicable.

\section{Funding}

No funding was received.

\section{Availability of data and materials}

The datasets used and/or analyzed during the present study are available from the corresponding author on reasonable request.

\section{Authors' contributions}

JM and HW drafted the manuscript. JM, HW and XW were mainly devoted to collecting and interpreting the data. XW and PS were responsible for PCR and MTT assays. All authors read and approved the final study.

\section{Ethics approval and consent to participate}

The study was approved by the Ethics Committee of The First Hospital of Jilin University (Changchun, China). Signed informed consents were obtained from the patients or the guardians.

\section{Patient consent for publication}

Not applicable.

\section{Competing interests}

The authors declare that they have no competing interests.

\section{References}

1. Li H, Xie S, Liu M, Chen Z, Liu X, Wang L, Li D and Zhou Y: The clinical significance of downregulation of mir-124-3p, mir-146a-5p, mir-155-5p and mir-335-5p in gastric cancer tumorigenesis. Int J Oncol 45: 197-208, 2014.

2. Maiarù M, Morgan $\mathrm{OB}$, Tochiki KK, Hobbiger EJ, Rajani K, Overington DW and Géranton SM: Complex regulation of the regulator of synaptic plasticity histone deacetylase 2 in the rodent dorsal horn after peripheral injury. J Neurochem 138 222-232, 2016

3. Wang SE, Ko SY, Jo S, Choi M, Lee SH, Jo HR, Seo JY, Lee SH, Kim YS, Jung SJ, et al: TRPV1 regulates stress responses through HDAC2. Cell Rep 19: 401-412, 2017.

4. Wang X, Li Y, Dai Y, Liu Q, Ning S, Liu J, Shen Z, Zhu D, Jiang F, Zhang J, et al: Sulforaphane improves chemotherapy efficacy by targeting cancer stem cell-like properties via the miR-124/IL-6R/STAT3 axis. Sci Rep 6: 36796, 2016.
5. Zhang Y, Li H, Han J and Zhang Y: Down-regulation of microRNA-124 is correlated with tumor metastasis and poor prognosis in patients with lung cancer. Int J Clin Exp Pathol 8: 1967-1972, 2015

6. Wang M, Gu H, Wang S, Qian H, Zhu W, Zhang L, Zhao C, Tao Y and Xu W: Circulating miR-17-5p and miR-20a: Molecular markers for gastric cancer. Mol Med Rep 5: 1514-1520, 2012.

7. Pei L, Xia JZ, Huang HY, Zhang RR, Yao LB, Zheng L and Hong B: Role of miR-124a methylation in patients with gastric cancer. Zhonghua Wei Chang Wai Ke Za Zhi 14: 136-139, 2011 (In Chinese).

8. Xie L, Zhang Z, Tan Z, He R, Zeng X, Xie Y, Li S, Tang G, Tang $\mathrm{H}$ and $\mathrm{He} \mathrm{X}$ : MicroRNA-124 inhibits proliferation and induces apoptosis by directly repressing EZH2 in gastric cancer. Mol Cell Biochem 392: 153-159, 2014

9. Xiao HJ, Ji Q, Yang L, Li RT, Zhang C and Hou JM: In vivo and in vitro effects of microRNA-124 on human gastric cancer by targeting JAG1 through the Notch signaling pathway. J Cell Biochem 119: 2520-2534, 2018

10. Zhang TH, Liang LZ, Liu XL, Wu JN, Su K, Chen JY, Zheng QY, Huang HZ and Liao GQ: Long non-coding RNA MALAT1 interacts with miR-124 and modulates tongue cancer growth by targeting JAG1. Oncol Rep 37: 2087-2094, 2017.

11. Liu L, Ye JX, Qin YZ, Chen QH and Ge LY: Evaluation of miR-29c, miR-124, miR-135a and miR-148a in predicting lymph node metastasis and tumor stage of gastric cancer. Int J Clin Exp Med 8: 22227-22236, 2015.

12. Livak KJ and Schmittgen TD: Analysis of relative gene expression data using real-time quantitative PCR and the 2(-Delta Delta C(T)) method. Methods 25: 402-408, 2001

13. Costa WL Jr, Coimbra FJ, Fogaroli RC, Ribeiro HS, Diniz AL, Begnami MD, Mello CA, Fanelli MF, Silva MJ, Fregnani JH, et al: Adjuvant chemoradiotherapy after d2-lymphadenectomy for gastric cancer: The role of n-ratio in patient selection. results of a single cancer center. Radiat Oncol 7: 169, 2012

14. Chen W, Zheng R, Baade PD, Zhang S, Zeng H, Bray F, Jemal A, Yu XQ and He J: Cancer statistics in China, 2015. CA Cancer J Clin 66: 115-132, 2016.

15. Zhou J, Zhou J, Wang W, Li W, Wu L, Li G, Shi J and Zhou S: The polymorphism in miR-25 attenuated the oncogenic function in gastric cancer. Tumour Biol 37: 5515-5520, 2016.

16. Maeda M, Yamashita S, Shimazu T, Iida N, Takeshima H, Nakajima T, Oda I, Nanjo S, Kusano C, Mori A, et al: Novel epigenetic markers for gastric cancer risk stratification in individuals after Helicobacter pylori eradication. Gastric Cancer 1113: 1-11, 2018.

17. Yuan Q, Sun T, Ye F, Kong W and Jin H: MicroRNA-124-3p affects proliferation, migration and apoptosis of bladder cancer cells through targeting AURKA. Cancer Biomark 19: 93-101, 2017.

18. Huang T, Zhou Y, Zhang J, Wong CC, Li W, Kwan JSH, Yang R, Chan AKY, Dong Y, Wu F, et al: SRGAP1, a crucial target of miR-340 and miR-124, functions as a potential oncogene in gastric tumorigenesis. Oncogene 37: 1159-1174, 2018.

19. Hu CB, Li QL, Hu JF, Zhang Q, Xie JP and Deng L: miR-124 inhibits growth and invasion of gastric cancer by targeting ROCK1. Asian Pac J Cancer Prev 15: 6543-6546, 2014.

20. Pan Y, Wu A, Xu F, Chen C, Jiang L and Jin R: Lentivirus-mediated overexpression of miR-124 suppresses growth and invasion by targeting JAG1 and EZH2 in gastric cancer. Oncol Lett 15: 7450-7458, 2018.

21. Li SL, Gao HL, Lv XK, Hei YR, Li PZ, Zhang JX and Lu N: MicroRNA-124 inhibits cell invasion and epithelial-mesenchymal transition by directly repressing Snail2 in gastric cancer. Eur Rev Med Pharmacol Sci 21: 3389-3396, 2017.

22. Xia J, Wu Z, Yu C, He W, Zheng H, He Y, Jian W, Chen L, Zhang L and Li W: miR-124 inhibits cell proliferation in gastric cancer through down-regulation of SPHK1. J Pathol 227: 470-480, 2012.

23. Jiang L, Lin T, Xu C, Hu S, Pan Y and Jin R: miR-124 interacts with the Notch1 signalling pathway and has therapeutic potential against gastric cancer. J Cell Mol Med 20: 313-322, 2016.

This work is licensed under a Creative Commons Attribution-NonCommercial-NoDerivatives 4.0 International (CC BY-NC-ND 4.0) License. 